\title{
Stress Enhances Retrieval of Drug-Related Memories in Abstinent Heroin Addicts
}

\author{
Li-Yan Zhao', Jie Shi', Xiao-Li Zhang', David H Epstein ${ }^{2}$, Xiang-Yang Zhang ${ }^{3}$, Yu Liu', Thomas R Kosten ${ }^{3}$ and \\ Lin Lu*, I \\ 'National Institute on Drug Dependence, Peking University, Beijing, China; ${ }^{2}$ Intramural Research Program, National Institute on Drug Abuse, \\ National Institutes of Health, Baltimore, MD, USA; ${ }^{3}$ Division of Alcohol and Addictive Disorders, Baylor College of Medicine, Houston, TX, USA
}

\begin{abstract}
Stress is associated with relapse to drugs after abstinence, but the mechanisms for this association are unclear. One mechanism may be that stress enhances abstinent addicts' recall of memories of drugs as stress relievers. This study assessed the effects of stress on free recall and cued recall of 10 heroin-related and 10 neutral words learned $24 \mathrm{~h}$ earlier by 102 abstinent heroin addicts. These participants were randomly assigned to three experiments that also assessed attention and working memory. Experiment I used a psychosocial stressor (Trier social stress test (TSST)) before testing for recall of heroin-related words. Experiment 2 added administration of the $\beta$-adrenoceptor antagonist propranolol I h before the psychosocial stressor. Experiment 3 added administration of either cortisol with propranolol, cortisol alone, or propranolol alone I h before word recall to determine whether stress enhancement of heroin-related word recall required noradrenergic-glucocorticoid interactions. We found that free recall of heroin-related words in abstinent addicts was enhanced after stress or cortisol administration when compared with a non-stress condition or placebo, respectively, whereas these interventions had no effect on neutral word recall. $\beta$-adrenergic blockade blocked the enhancing effect of stress or cortisol on free recall of heroin-related words. Neither stress nor cortisol affected cued recall, attention, or working memory. The potential of $\beta$-adrenergic blockade to reduce or block stress-induced enhancement of drug-related memory retrieval may be relevant to preventing stress-induced relapse in abstinent heroin addicts.
\end{abstract}

Neuropsychopharmacology (2010) 35, 720-726; doi:I0.I038/npp.2009. I79; published online 4 November 2009

Keywords: stress; cortisol; heroin-related memory retrieval; norepinephrine

\section{INTRODUCTION}

Stress is associated with relapse to drugs after abstinence, but the mechanisms for this association are unclear. One mechanism may be that stress enhances abstinent addicts' recall of drugs as stress relievers. A large number of studies from humans and laboratory animals have shown that memory retrieval is affected by stress and stress hormones (de Quervain et al, 2009; Roozendaal, 2002) that can impair or enhance memory, depending on several modulatory variables (Cai et al, 2006; de Kloet et al, 1999; Sandi, 1998; Wolf, 2003). Previous drug dependence seems to be one of these modulatory variables (Bossert et al, 2005; Hyman et al, 2007; Sinha, 2001).

Studies in healthy subjects indicate that glucocorticoids in the presence of noradrenergic activation enhance memory consolidation (Roozendaal et al, 1999), but impair retrieval of neutral memories and information (de Quervain et al,

* Correspondence: Professor L Lu, National Institute on Drug Dependence, Peking University, 38 Xueyuan Road, Beijing China, Tel: 86-10-82802459, Fax: 86-10-62032624, E-mail: linlu@bjmu.edu.cn Received 31 May 2009; revised 22 September 2009; accepted 23 September 2009
1998; Kuhlmann et al, 2005). However, drug-related memories are not neutral in chronic heroin abusers. Thus, during abstinence, stress may selectively spare (or even enhance) recall of drug-related memories; indeed, addiction may be considered an aberrant form of learning and memory that is biased toward drug-related information (Hyman, 2005; Franken et al, 2000a; Franken et al, 2000b; Waters and Feyerabend, 2000). Therefore, we hypothesized that stress or glucocorticoids administered immediately before a free-recall test would enhance retrieval of drugrelated memories relative to neutral memories in abstinent addicts, whereas this difference would not be found in normal controls.

Previous studies have indicated that noradrenergic activation has a key role in glucocorticoid effects on memory retrieval such that glucocorticoid effects on memory retrieval can be blocked by concurrent injections of the $\beta$-adrenoceptor antagonist propranolol (Quirarte et al, 1997; Roozendaal et al, 2004; de Quervain et al, 2007). Thus, in two further experiments, we tested whether $\beta$-noradrenergic blockade and direct glucocorticoid stimulation would influence or mimic the effects of stress on recall of heroin-related words in abstinent heroin addicts. 


\section{METHODS}

\section{Participants}

A total of 108 male in-patient abstinent heroin addicts were enrolled from the Addiction Treatment Center in Yichang, China. They were randomly assigned to three experiments to test the effect of stress on retrieval of heroin-related words. Each participant was permitted to take part in only one of the three experiments. Before enrollment, participants underwent thorough screening, including a medicalhistory interview, physical examination, and clinical laboratory tests (including ECG, blood chemistry, and urinalysis). Heroin abstinence was confirmed by urine toxicology screens twice weekly while they stayed in an inpatient facility, ensuring that each participant had been heroin free for a minimum of 1 month at study enrollment. Participants had to have met the DSM-IV criteria for heroin dependence before abstinence. Among the exclusion criteria were DSM-IV diagnosis of past history of any substance abuse/dependence (except nicotine and heroin) and current or past history of psychotic disorders; or risk factors for untoward side effects from propranolol and cortisol (ie, irregular heartbeats, history of cardiogenic shock, history of severe heart failure, asthma, or abnormal ECG or other laboratory findings). All participants were in-patients, and they were allowed to smoke up to four cigarettes per day. Because smoking can affect salivary cortisol levels, the participants were required to abstain from smoking for $10 \mathrm{~h}$ before the experiments. They completed a questionnaire about nicotine withdrawal before the experimental session, but none reported or showed withdrawal symptoms induced by abstinence from nicotine (data not shown). The study was conducted according to human-research guidelines and was approved by the research ethics board of the Peking University. All participants gave written informed consent before taking part in the study and were compensated after completion.

\section{Drug Administration}

Drug doses (de Quervain et al, 2007; Het et al, 2005) and timings (de Quervain et al, 2007) were selected on the basis of published pharmacokinetic data and previous studies that indicated that this dose of propranolol would interfere with memory retrieval. The cortisol dose was selected based on clinical experience of a dose that has detectable effects in humans and that would be expected to raise blood glucocorticoid levels to a similar extent as psychological stressors, such as the Trier social stress test (TSST) (Sinha, 2001, 2005). Propranolol (40 mg, Zhongnuo Pharma, China) and cortisol (50 mg, Shanghai Pharma, China) reach peak plasma concentrations approximately $1 \mathrm{~h}$ after oral administration and hence they were administered 1 before testing. The washout period of 4 weeks between sessions made carryover effects unlikely.

\section{Task Battery}

Trier social stress test (TSST) task. The TSST is a wellestablished laboratory stress paradigm that reliably produces a hypothalamic-pituitary-adrenal (HPA) response (Kirschbaum et al, 1993). The TSST began with a 2-min preparation period followed by 5 min of public speaking (a simulated job interview focusing on personal strengths and weaknesses) in front of two staff members (one man and one woman wearing formal white coats) whom the participants had not previously met. Immediately after 5 min of speaking, the participants were asked to do mental arithmetic (ie, counting backward from 2308 by 13) aloud in front of these two staff for 5 min (Dickerson and Kemeny, 2004; Kuhlmann et al, 2005). In addition, the participants were videotaped. The control condition consisted of talking to a familiar tester for $5 \mathrm{~min}$ about a movie or a book followed by $5 \mathrm{~min}$ of rest.

Word recall. A word list (with two parallel versions available), containing 10 heroin-related (eg, heroin, syringe) and 10 neutral nondrug (eg, office, charger) words, was presented to the participants on a piece of paper (Wechsler et al, 2002). There were no differences among the heroinrelated and neutral nondrug words with respect to word length. Heroin-related words were chosen from the lists of words that were provided by local heroin addicts. The neutral nondrug words were selected from a database of affective norms for Chinese words (Wang et al, 2008). Words were selected for non-ambiguity (to the extent possible) and familiarity among drug users. In a pilot study, 100 abstinent heroin patients (who did not participate in this study) accurately rated the intended valence of the heroin-related and neutral nondrug words that had similar familiarity for the participants. Moreover, the two lists resulted in similar learning and delayed-recall performance (Zhao et al, 2009).

Cued recall. Cued recall was assessed by randomly presenting a part of each learned word on a piece of paper, with instructions to complete the word stem with a previously learned word.

Working memory. Working memory was assessed with a digit-span test. Several series of digits of increasing length were read to the participants, who were required to repeat each series. Each set length was tested twice. A forward and a backward condition were used. Participants earned one point for each correctly repeated set (Liu et al, 2009; Lynn and Dai, 1993; Wechsler et al, 2002).

The d2 test of attention/psychomotor speed. From a series consisting of the letters $d$ and $p$, with either one or two lines above and/or below each letter, participants were asked to mark the $d s$ with two lines as quickly and accurately as possible. A summary score was calculated using the number of correctly marked $d s$ minus the number of errors (Brickenkamp, 1994).

\section{Salivary Cortisol Assessment}

Saliva was collected using Salivette collection devices (Sarstedt, Nümbrecht, Germany). Free cortisol levels were measured using a commercially available immunoassay (Immuno-Biological Laboratories, Furui Company, Beijing, China). Inter-assay and intra-assay variations were $<15 \%$. 


\section{Study Design and Procedure}

Experiment 1 effects of stress on recall of heroin-related words in abstinent heroin addicts. The study had a withinsubject design consisting of four sessions per participant, with each session occurring on a separate day (Figure 1). An interval of 4 weeks, during which the subject remained in residential treatment, separated sessions 1 and 2 from 3 and 4 (Figure 1a).

On day 1 , the participants arrived at the laboratory at 0830 hours. This was followed by a 30 -min adaptation period. At 0900 hours, they learned a list of 20 words (10 heroin-related and 10 neutral nondrug words). Participants were given $60 \mathrm{~s}$ to learn the words and were then asked to write down the words that they were able to recall. The same word list was immediately presented once more, and immediate free recall was tested again (Kuhlmann et al, 2005).

On day 2, the participants arrived at the laboratory and again had a 30-min adaptation period. Immediately after that, they were challenged with the TSST or underwent a control condition for $15 \mathrm{~min}$. They were then asked to write down the words that they had learned on the previous day. Free-recall tests were immediately followed by tests of cued recall, attention, and working memory. Salivary cortisol was measured before the TSST or control condition $(0 \mathrm{~min})$, immediately afterward $(+20 \mathrm{~min})$, immediately before cognitive testing $(+30 \mathrm{~min})$, and after cognitive testing (+50 min).

After 4 weeks, while remaining in residential treatment, the participants returned for days 3 and 4 sessions, during which the same procedures were repeated, with the alternate condition (TSST or control) and word list (two parallel versions), counterbalanced among participants (Figure 1a).

Experiment 2 effects of propranolol on stress-induced enhancement of heroin-related word recall. In a doubleblind, placebo-controlled design, the participants were randomly assigned to either propranolol ( $40 \mathrm{mg}$, Zhongnuo
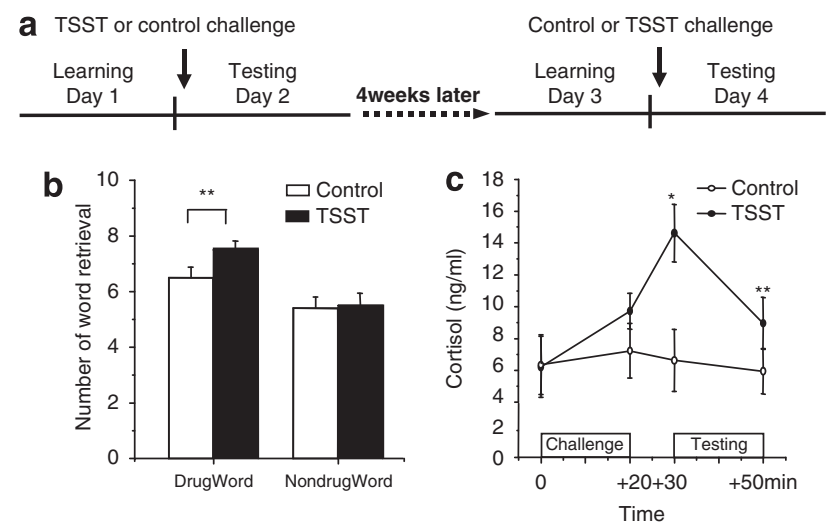

Figure I Effects of psychosocial stress on retrieval of heroin-related words. (a) Study procedure in experiment I. 'Testing' refers to the period of recall testing (for word lists learned $24 \mathrm{~h}$ earlier) as well as to the testing of cued recall, working memory, and attention. (b) Effects of stress on retrieval of heroin-related words. (c) Effects of stress on salivary cortisol concentrations. Data are shown as mean \pm SEM. Each list contained 10 words. $* P<0.01$, ** $P<0.05$ compared with control condition (post hoc t-tests). For additional statistical analyses, see Results.
Pharma) or placebo (Figure 2). The procedure was the same as in experiment 1 , except that on days 2 and 4 , the study drugs were administered once orally $1 \mathrm{~h}$ before the TSST or the control condition that was counterbalanced across participants (Figure 2a). Free recall was assessed immediately after the challenge. Cued recall, attention, and working memory were tested immediately after the free recall. Salivary cortisol was measured before study-drug administration $(-60 \mathrm{~min}), 1 \mathrm{~h}$ later (before TSST or control condition, $0 \mathrm{~min}$ ), immediately after the TSST or control condition $(+20 \mathrm{~min})$, immediately before cognitive testing ( + $30 \mathrm{~min})$, and after cognitive testing (+50 min).

Experiment 3 effects of propranolol and cortisol on heroin-related word recall. We used a double-blind, placebo-controlled design in which participants were randomly assigned to three groups: (1) cortisol $(50 \mathrm{mg})$ with propranolol $(40 \mathrm{mg}) /$ placebo, (2) cortisol $(50 \mathrm{mg}) /$ placebo, and (3) propranolol $(40 \mathrm{mg}) /$ placebo (Figure 3$)$. The procedure on days 1 and 3 was the same as in experiment 1 . On days 2 and 4 , the study drugs were administered once orally $1 \mathrm{~h}$ before the test, counterbalanced across participants (Figure 3a). At the estimated peak of the plasma concentration of the study drugs, we tested free recall for the words. Cued recall, attention, and working memory were tested immediately after the free
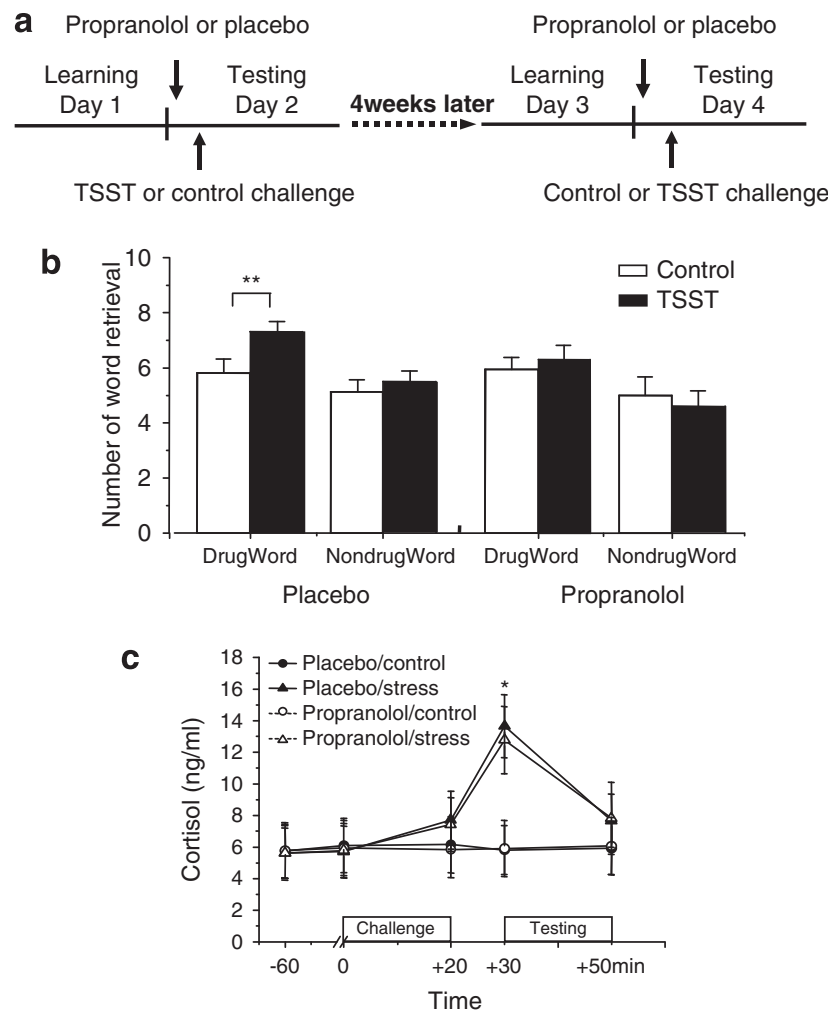

Figure 2 Effects of propranolol on stress-induced enhancement of retrieval of heroin-related words. (a) Study procedure in experiment 2. (b) Effects of propranolol on stress-induced enhancement of retrieval of heroin-related words. (c) Effects of stress and study drug on salivary cortisol concentrations. Data are represented as mean \pm SEM. Each list contained 10 words. $* P<0.01$, ** $P<0.05$ compared with control condition (post hoc t-tests). For additional statistical analyses, see Results. 
Placebo or drug

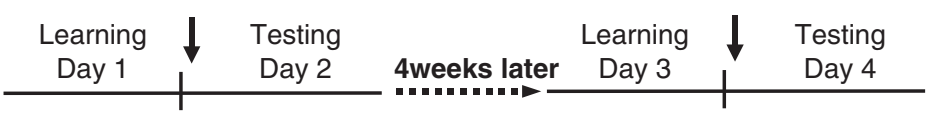

b
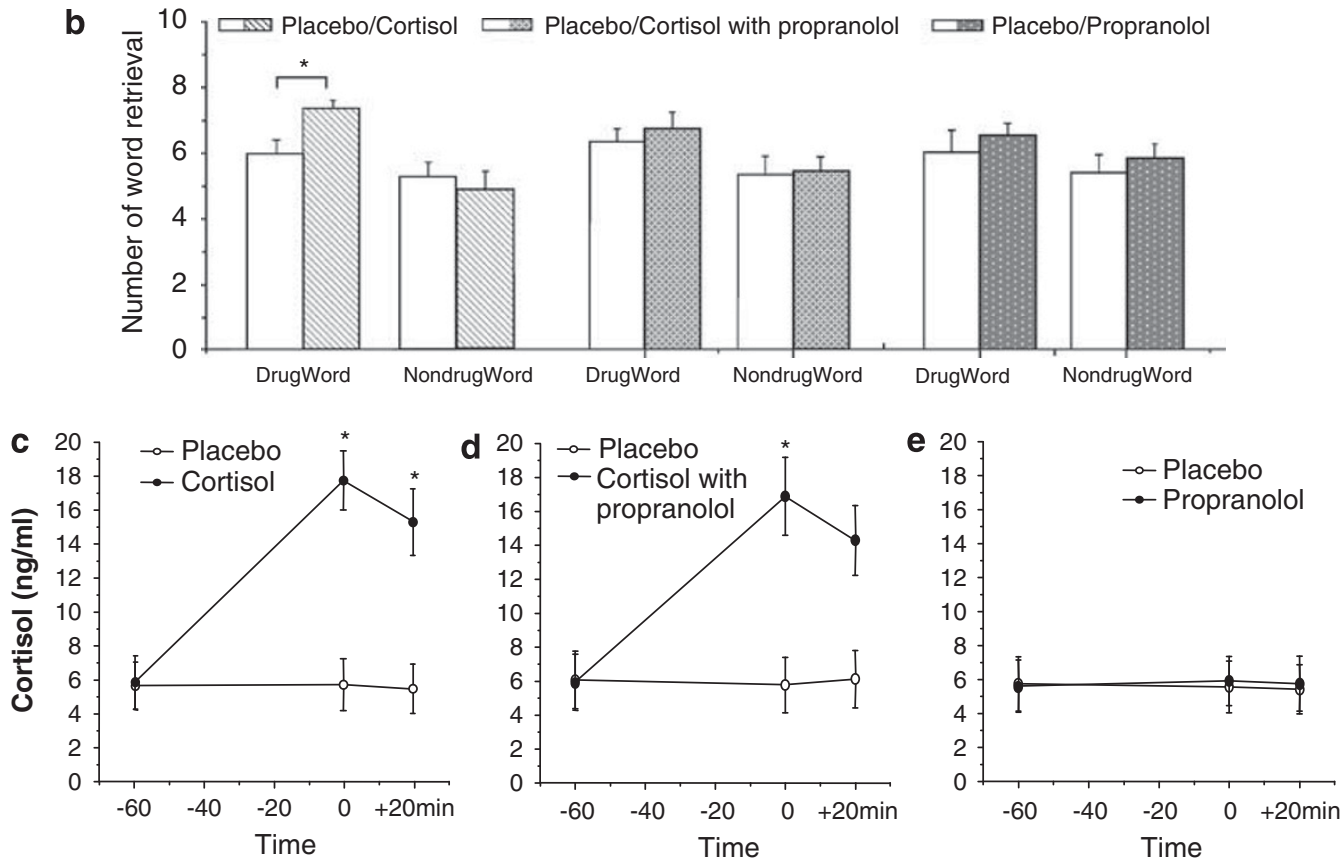

Figure 3 Effects of propranolol and cortisol on retrieval of heroin-related words. (a) Study procedure in experiment 3. 'Drug' refers to administration of cortisol, cortisol with propranolol, or propranolol; for details, see Materials and Methods. (b) Effects of propranolol and cortisol on retrieval of heroin-related words. (c-e) Effects of study drugs on salivary cortisol concentrations. Data are shown as mean $\pm \mathrm{SEM}$. $* P<0.0$ l compared with placebo treatment condition (post hoc t-tests). For additional statistical analyses, see Results.

recall. Salivary cortisol was measured before study-drug administration ( $-60 \mathrm{~min}), 1 \mathrm{~h}$ later (before the test, $0 \mathrm{~min})$, and immediately after the test $(+20 \mathrm{~min})$.

\section{Statistical Analysis}

Demographic characteristics among groups were compared using one-way analysis of variance (ANOVA). ANOVAs for repeated measurements were used to analyze word recall and salivary cortisol levels. Two-way ANOVAs or paired $t$-tests were used to analyze other measures (cued recall, attention, and working memory). Follow-up analysis of ANOVA results was carried out using post hoc pairwise comparisons with Fisher's least significant difference (LSD). Significance levels were set at $P<0.05$.

\section{RESULTS}

\section{Participants}

Our final sample size was 102 because of two individuals leaving before being randomized and four others leaving the addiction treatment center during the study. Participants were between 20 and $39(29.6 \pm 5.0$, mean \pm SD) years of age and had been drug free for a minimum of 1 month, average $3.13 \pm 1.9$ (mean $\pm \mathrm{SD}$ ) months. They had a mean lifetime history of regular heroin use of $5.9 \pm 3.4$ (mean \pm SD) years and an average of $0.66 \pm 0.38 \mathrm{~g}$ (mean $\pm \mathrm{SD})$ per day. The
102 participants were assigned to three experiments as follows. In experiment $1(n=22)$, we tested the effect of psychosocial stress on heroin-related memory retrieval. In experiment $2(n=32)$, we randomly assigned participants to two subgroups who were administered either propranolol $(n=16)$ or placebo $(n=16)$ at $1 \mathrm{~h}$ before the psychosocial stress to test the effect of propranolol on stress-influenced recall. In experiment $3(n=48)$, we randomly assigned participants to three groups who were administered: (1) cortisol with propranolol $(n=15)$, (2) cortisol/placebo $(n=17)$, or (3) propranolol/placebo $(n=16)$ to test the effect of propranolol and cortisol on recall. The demographics are summarized in Table 1.

\section{Effects of Stress on Recall of Heroin-Related Words}

Word retrieval. An ANOVA with two repeated-measurement factors, challenge (stress and control) and valence (heroin-related and neutral), showed a significant main effect of challenge $\left(\mathrm{F}_{(1,21)}=10.96, P<0.01\right)$. Post hoc $t$-tests showed that significantly more heroin-related words were retrieved under the stress condition than under the control condition $(P<0.05)$, but there was no such enhancement for neutral nondrug words $(P>0.10$; Figure $1 \mathrm{~b})$.

Salivary cortisol levels. An ANOVA with two repeatedmeasurement factors, challenge (stress and control) and time $(0,+20,+30$, and $+50 \mathrm{~min})$, revealed a significant 
Table I Demographic Characteristics of Participants

\begin{tabular}{|c|c|c|c|c|c|c|c|}
\hline \multirow{2}{*}{ Characteristic } & \multirow{2}{*}{$\begin{array}{l}\text { Experiment I } \\
\qquad(N=22)\end{array}$} & \multicolumn{2}{|c|}{ Experiment $2(N=32)$} & \multicolumn{3}{|c|}{ Experiment $3(N=48)$} & \multirow{2}{*}{$P$-value } \\
\hline & & $\begin{array}{c}\text { Propranolol } \\
(N=16)\end{array}$ & $\begin{array}{l}\text { Placebo } \\
(N=16)\end{array}$ & $\begin{array}{l}\text { Cortisol } \\
(N=17)\end{array}$ & $\begin{array}{l}\text { C with P } \\
(N=15)\end{array}$ & $\begin{array}{c}\text { Propranolol } \\
(N=16)\end{array}$ & \\
\hline Age (years) & $30.45 \pm 4.37$ & $28.61 \pm 5.35$ & $27.88 \pm 4.32$ & $30.52 \pm 4.73$ & $30.22 \pm 5.40$ & $29.80 \pm 5.91$ & 0.61 \\
\hline Education (years) & $8.55 \pm 1.77$ & $9.60 \pm 1.92$ & $9.75 \pm 2.57$ & $9.20 \pm 1.56$ & $9.40 \pm 2.31$ & $9.11 \pm 1.90$ & 0.91 \\
\hline Months of heroin abstinence & $3.41 \pm 1.07$ & $3.13 \pm 1.76$ & $2.78 \pm 1.24$ & $3.20 \pm 2.61$ & $3.22 \pm 2.70$ & $3.11 \pm 2.20$ & 0.98 \\
\hline
\end{tabular}

Abbreviation: C with $\mathrm{P}$, cortisol with propranolol.

All results are mean \pm SD. Experiment I, individuals given psychosocial stress; Experiment 2, participants were randomly assigned to two subgroups: administered propranolol $(n=16)$ or placebo $(n=16)$ at I h before psychosocial stress; Experiment 3, participants were randomly assigned to three subgroups: administered cortisol $(n=17)$, cortisol with propranolol $(n=15)$, or propranolol alone $(n=16)$.

interaction of challenge $\times$ time $\left(\mathrm{F}_{(3,63)}=7.8, P<0.01\right)$. Post hoc $t$-tests between the stress and control conditions showed significantly higher cortisol concentrations at $+30 \mathrm{~min}$ and at $+50 \mathrm{~min}$ (all $P$-values $<0.05$, Figure $1 \mathrm{c}$ ).

\section{Propranolol Reduced Stress-Induced Enhancement of Heroin-Related Word Recall}

Word retrieval. Repeated-measures ANOVAs with the between-subject factor group (placebo and propranolol) and the within-subject factors challenge (stress and control) and valence (heroin-related and neutral) showed a main effect of valence $\left(\mathrm{F}_{(1,31)}=18.41 ; P<0.01\right)$ and a group $\times$ challenge $\times$ valence interaction $\left(\mathrm{F}_{(4,28)}=2.96 ; P<0.05\right)$. Post hoc analysis showed that participants given placebo recalled significantly more heroin-related words under the stress condition than the control condition $(P<0.05)$; there was no such difference in recall of neutral words $(P>0.10$; Figure $2 b)$. In the placebo but not the propranolol condition, stress significantly enhanced recall of heroin-related compared with neutral words. Thus, propranolol blocked stress-enhanced recall of heroin-related words.

Salivary cortisol levels. Repeated-measures ANOVAs showed a significant challenge effect $\left(\mathrm{F}_{(1,31)}=19.63\right.$, $P<0.001)$. Post hoc $t$-tests between the stress and control conditions showed significantly higher cortisol concentrations at $+30 \mathrm{~min}$ in both the placebo group and the propranolol group (all $P$-values $<0.01$, Figure $2 \mathrm{c}$ ).

\section{Effects of Propranolol and Cortisol on Recall of Heroin-Related Words}

Word retrieval. In the first subgroup, an ANOVA with two repeated-measurement factors, treatment (cortisol and placebo) and valence (heroin-related and neutral), showed a main effect of valence $\left(\mathrm{F}_{(1,16)}=23.12, P<0.01\right)$ and a significant interaction of treatment $\times$ valence $\left(\mathrm{F}_{(1,16)}=7.13\right.$, $P<0.05)$. Post hoc $t$-tests showed that cortisol significantly increased retrieval of heroin-related words when compared with placebo $(P=0.01)$, but had no effect on retrieval of neutral words $(P>0.10$; Figure $3 b)$. In the second and third subgroup, repeated-measure ANOVAs with the factors treatment (drug and placebo) and valence (heroin-related and neutral) showed no significant differences in either subgroup (all $P$-values $>0.10$, Figure $3 b$ ).

Salivary cortisol levels. In the first subgroup, an ANOVA with two repeated-measurement factors, treatment (cortisol and placebo) and time $(-60,0$, and $+20 \mathrm{~min})$, showed a significant treatment effect $\left(\mathrm{F}_{(1,16)}=85.71, P<0.01\right)$, time effect $\left(\mathrm{F}_{(2,32)}=20.64, P<0.01\right)$, and treatment $\times$ time interaction $\left(\mathrm{F}_{(2,32)}=20.63, P<0.01\right)$. Post hoc $t$-tests showed that the significant differences from placebo occurred at 0 and $+20 \mathrm{~min}$ (all $P$-values $<0.01$, Figure $3 \mathrm{c}$ ). In subgroup 2, repeated-measures ANOVAs showed a significant overall effect of drug condition on salivary cortisol (time effect, $\mathrm{F}_{(2,28)}=32.09, \quad P<0.01$; treatment effect, $\mathrm{F}_{(1,14)}=101.32$, $P<0.01$; treatment $\times$ time interaction, $\mathrm{F}_{(2,28)}=27.54$, $P<0.01)$. Post hoc $t$-tests showed that cortisol concentrations at 0 and at $+20 \mathrm{~min}$ were increased in the cortisol with propranolol group (all $P$-values $<0.01$, Figure $3 \mathrm{~d}$ ). In subgroup 3, repeated-measures ANOVAs showed no significant difference (all $P$-values $>0.05$, Figure $3 e$ )

Other cognitive measures. The stress challenge had no effect on measures of cued recall, working memory, or attention (all $P$-values $>0.05$ ) in the three experiments (data not shown). There were no significant differences in learning of the words on days 1 or 3 (all $P$-values $>0.05$ ). No participant reported any adverse effects of drug administration or stress manipulations.

\section{DISCUSSION}

This study had three key findings in abstinent heroin addicts. (1) Psychosocial stress enhanced recall of heroinrelated words whereas had no effect on recall of neutral nondrug words. (2) Exogenously administered cortisol had effects similar to those of psychosocial stress. (3) The $\beta$-adrenoceptor antagonist propranolol blocked the psychosocial stress enhancement and the cortisol enhancement of heroin-related word recall. These findings suggest that exposure to stress enhances heroin-related memory 
retrieval in abstinent heroin addicts, and that this effect is mediated by a glucocorticoid mechanism that also requires $\beta$-adrenergic stimulation.

\section{Effects of Stress on Retrieval of Heroin-Related Words}

Our finding that psychosocial stress enhances recall of drug-related words in abstinent heroin addicts is the opposite of previous findings in healthy subjects, in whom psychological stress or cortisol administration impairs free recall of emotional words but not of neutral words (de Quervain et al, 2000; Kuhlmann et al, 2005; Wolf et al, 2004). Although we have no obvious explanation for this difference, one possibility is that heroin addicts do not simply recognize these heroin-related words as emotional. Instead, these words activate an aberrant form of overarousing memory that is associated with stress and glucocorticoid activation. For example, stress or corticosterone administration before or during training in a behavioral task enhances later memory retrieval when corticosterone or stress again is administered before the later probe trial (Yang et al, 2003). Furthermore, the more stress experienced before or during the behavioral training, the greater the enhancement of retrieval by the later administration of stress (Yang et al, 2003). Similarly, chronic heroin abuse and its associated stressors, such as of recurrent withdrawal symptoms, could enhance later recall of drug-related memories in the context of a psychosocial stress during abstinence, as was observed in this study. Thus, glucocorticoid activation during the initial learning of associations between stress and drug use (and its associated vocabulary) may be necessary for stress enhancement of memory recall during abstinence. Abstinence, similar to exposure to stressors, can stimulate the HPA axis; the consequent release of glucocorticoids may itself serve as an internal cue that reminds the individual about the abused substance and its stress-relieving qualities (Goeders, 2002, 2003; Sinha 2007; Gisquet-Verrier et al, 2004; Nader et al, 2000).

The effects that we observed on word recall were not attributable to general cognitive abnormalities in the abstinent addicts; in the same participants, we found no significant effects of stress or study drugs on tests of cued recall, attention, and working memory. These results are consistent with a previous study in which general cognition was not affected by TSST challenge (Kuhlmann et al, 2005).

\section{Propranolol Reduced Stress-Enhanced or Cortisol-Enhanced Recall of Heroin-Related Words}

Our finding that the $\beta$-adrenoceptor antagonist propranolol selectively blocked the enhancing effect of stress or exogenous cortisol on retrieval of heroin-related words is consistent with findings that glucocorticoid modulation of memory depends on concurrent increases in central noradrenergic transmission (Roozendaal et al, 2002, 2004, 2006; Cahill et al, 1994, 1996; de Quervain et al, 2007; Okuda et al, 2004; Quirarte et al, 1997, 1998; Adolphs and Tranel, 2000; Pelletier et al, 2005; McIntyre et al, 2002; van Stegeren et al, 2005). However, as previously shown in humans (de Quervain et al, 2007), propranolol alone did not affect memory retrieval. Thus, $\beta$-adrenoceptor antagonists might prove clinically useful for preventing the effects of stress and glucocorticoid release on recall of heroin-related memories.

The limitations of this study included the absence of a healthy control group and of women. However, our pretest showed no significant difference in valence between drugrelated and nondrug words for healthy controls (data not shown), and we showed that healthy controls when stressed showed no difference in recall of drug-related and nondrug words. We had limited this first study to men because women heroin addicts are relatively uncommon in China and previous work in laboratory animals and humans has indicated that stress can affect memory differently between the sexes (Conrad et al, 2004; Shors, 2004; Li et al, 2005). Thus, future studies will need to examine sex differences in the effects that were found in this study.

In summary, we found that stress or glucocorticoids significantly enhanced recall of drug-related words in abstinent heroin addicts. The cortisol enhancement seemed to require concurrent activation of $\beta$-adrenergic receptors. These findings may have important clinical implication, as the potential to reduce or block stress-enhanced recall of drug-related memories using $\beta$-adrenoceptor antagonists should be considered for the prevention of stress-induced relapse in abstinent heroin addicts.

\section{ACKNOWLEDGEMENTS}

This work was supported by the National Basic Research Program of China (973 Program, 2007CB512302 and 2009CB522000) and the Natural Science Foundation of China (No. 30670713 and 30725016). We thank Dr Yanping Bao for technical assistance and Dr Yavin Shaham for comments on the paper.

\section{DISCLOSURE}

The authors declare that, except for income received from their primary employer, no financial support or compensation has been received from any individual or corporate entity over the past three years for research or professional service and there are no personal financial holdings that could be perceived as constituting a potential conflict of interest.

\section{REFERENCES}

Adolphs R, Tranel D (2000). The Amygdala 2nd edn. Oxford University: New York.

Bossert JM, Ghitza UE, Lu L, Epstein DH, Shaham Y (2005). Neurobiology of relapse to heroin and cocaine seeking: an update and clinical implications. Eur J Pharmacol 526: 36-50.

Brickenkamp R (1994). Test d2: Aufmerksamkeits-Belastungs-Test; Handanweisungen. Germany: Hogrefe.: Göttingen..

Cahill L, Haier RJ, Fallon J, Alkire MT, Tang C, Keator D et al. (1996). Amygdala activity at encoding correlated with long-term, free recall of emotional information. Proc Natl Acad Sci USA 93: 8016-8021.

Cahill L, Prins B, Weber M, McGaugh JL (1994). Beta-adrenergic activation and memory for emotional events. Nature 371: 702-704. 
Cai WH, Blundell J, Han J, Greene RW, Powell CM (2006). Postreactivation glucocorticoids impair recall of established fear memory. J Neurosci 26: 9560-9566.

Conrad CD, Jackson JL, Wieczorek L, Baran SE, Harman JS, Wright RL et al. (2004). Acute stress impairs spatial memory in male but not female rats: influence of estrous cycle. Pharmacol Biochem Behav 78: 569-579.

de Kloet ER, Oitzl MS, Joels M (1999). Stress and cognition: are corticosteroids good or bad guys? Trends Neurosci 22: 422-426.

de Quervain DJ, Aerni A, Roozendaal B (2007). Preventive effect of beta-adrenoceptor blockade on glucocorticoid-induced memory retrieval deficits. Am J Psychiatry 164: 967-969.

de Quervain DJ, Aerni A, Schelling G, Roozendaal B (2009). Glucocorticoids and the regulation of emotional memory in health and disease. Front Neuroendocrinol 30: 358-370.

de Quervain DJ, Roozendaal B, McGaugh JL (1998). Stress and glucocorticoids impair retrieval of long-term spatial memory. Nature 394: 787-790.

de Quervain DJ, Roozendaal B, Nitsch RM, McGaugh JL, Hock C (2000). Acute cortisone administration impairs retrieval of longterm declarative memory in humans. Nat Neurosci 3: 313-314.

Dickerson SS, Kemeny ME (2004). Acute stressors and cortisol responses: a theoretical integration and synthesis of laboratory research. Psychol Bull 130: 355-391.

Franken IH, Kroon LY, Hendriks VM (2000a). Influence of individual differences in craving and obsessive cocaine thoughts on attentional processes in cocaine abuse patients. Addict Behav 25: 99-102.

Franken IH, Kroon LY, Wiers RW, Jansen A (2000b). Selective cognitive processing of drug cues in heroin dependence. J Psychopharmacol 14: 395-400.

Gisquet-Verrier P, Botreau F, Venero C, Sandi C (2004). Exposure to retrieval cues improves retention performance and induces changes in ACTH and corticosterone release. Psychoneuroendocrinology 29: 529-556.

Goeders NE (2002). The HPA axis and cocaine reinforcement. Psychoneuroendocrinology 27: 13-33.

Goeders NE (2003). The impact of stress on addiction. Eur Neuropsychopharmacol 13: 435-441.

Het S, Ramlow G, Wolf OT (2005). A meta-analytic review of the effects of acute cortisol administration on human memory. Psychoneuroendocrinology 30: 771-784.

Hyman SE (2005). Addiction: a disease of learning and memory. Am J Psychiatry 162: 1414-1422.

Hyman SM, Fox H, Hong KI, Doebrick C, Sinha R (2007). Stress and drug-cue-induced craving in opioid-dependent individuals in naltrexone treatment. Exp Clin Psychopharmacol 15: 134-143.

Kirschbaum C, Pirke KM, Hellhammer DH (1993). The 'Trier Social Stress Test'-a tool for investigating psychobiological stress responses in a laboratory setting. Neuropsychobiology 28: 76-81.

Kuhlmann S, Piel M, Wolf OT (2005). Impaired memory retrieval after psychosocial stress in healthy young men. J Neurosci 25: 2977-2982.

Li CS, Kosten TR, Sinha R (2005). Sex differences in brain activation during stress imagery in abstinent cocaine users: a functional magnetic resonance imaging study. Biol Psychiatry 57: 487-494.

Liu Y, Sun HQ, Bao YP, Li SX, Beveridge TJ, Di XL et al. (2009). Subjective, cognitive/psychomotor, and physiological effects of aripiprazole in Chinese light and heavy smokers. Drug Alcohol Depend 101: 42-52.

Lynn R, Dai XY (1993). Sex differences on the Chinese standardization sample of the WAIS-R. J Genet Psychol 154: 459-463.

McIntyre CK, Hatfield T, McGaugh JL (2002). Amygdala norepinephrine levels after training predict inhibitory avoidance retention performance in rats. Eur J Neurosci 16: 1223-1226.
Nader K, Schafe GE, LeDoux JE (2000). The labile nature of consolidation theory. Nat Rev Neurosci 1: 216-219.

Okuda S, Roozendaal B, McGaugh JL (2004). Glucocorticoid effects on object recognition memory require training-associated emotional arousal. Proc Natl Acad Sci USA 101: 853-858.

Pelletier JG, Likhtik E, Filali M, Pare D (2005). Lasting increases in basolateral amygdala activity after emotional arousal: implications for facilitated consolidation of emotional memories. Learn Mem 12: 96-102.

Quirarte GL, Galvez R, Roozendaal B, McGaugh JL (1998). Norepinephrine release in the amygdala in response to footshock and opioid peptidergic drugs. Brain Res 808: 134-140.

Quirarte GL, Roozendaal B, McGaugh JL (1997). Glucocorticoid enhancement of memory storage involves noradrenergic activation in the basolateral amygdala. Proc Natl Acad Sci USA 94: 14048-14053.

Roozendaal B (2002). Stress and memory: opposing effects of glucocorticoids on memory consolidation and memory retrieval. Neurobiol Learn Mem 78: 578-595.

Roozendaal B, Hahn EL, Nathan SV, de Quervain DJ, McGaugh JL (2004). Glucocorticoid effects on memory retrieval require concurrent noradrenergic activity in the hippocampus and basolateral amygdala. J Neurosci 24: 8161-8169.

Roozendaal B, Nguyen BT, Power AE, McGaugh JL (1999). Basolateral amygdala noradrenergic influence enables enhancement of memory consolidation induced by hippocampal glucocorticoid receptor activation. Proc Natl Acad Sci USA 96: 11642-11647.

Roozendaal B, Okuda S, de Quervain DJ, McGaugh JL (2006). Glucocorticoids interact with emotion-induced noradrenergic activation in influencing different memory functions. Neuroscience 138: 901-910.

Sandi C (1998). The role and mechanisms of action of glucocorticoid involvement in memory storage. Neural Plast 6: 41-52.

Shors TJ (2004). Learning during stressful times. Learn Mem 11: 137-144.

Sinha R (2001). How does stress increase risk of drug abuse and relapse? Psychopharmacology (Berl) 158: 343-359.

Sinha R (2005). Handbook of Stress and the Brain. Vol 15. Elsevier: Amsterdam.

Sinha R (2007). The role of stress in addiction relapse. Curr Psychiatry Rep 9: 388-395.

van Stegeren AH, Goekoop R, Everaerd W, Scheltens P, Barkhof F, Kuijer JP et al. (2005). Noradrenaline mediates amygdala activation in men and women during encoding of emotional material. Neuroimage 24: 898-909.

Wang YN, Zhou LM, Luo YJ (2008). The pilot establishment and evaluation of Chinese affective word system. Chin Ment Health J 22: 608-612.

Waters AJ, Feyerabend C (2000). Determinants and effects of attentional bias in smokers. Psychol Addict Behav 14: $111-120$.

Wechsler D, Chen YH, Chen XY (2002). (eds) WAIS-III Chinese Version Technical Manual. Psychological Corporation: San Antonio, TA.

Wolf OT (2003). HPA axis and memory. Best Pract Res Clin Endocrinol Metab 17: 287-299.

Wolf OT, Kuhlmann S, Buss C, Hellhammer DH, Kirschbaum C (2004). Cortisol and memory retrieval in humans: influence of emotional valence. Ann NY Acad Sci 1032: 195-197.

Yang Y, Cao J, Xiong W, Zhang J, Zhou Q, Wei H et al. (2003). Both stress experience and age determine the impairment or enhancement effect of stress on spatial memory retrieval. J Endocrinol 178: 45-54.

Zhao LY, Zhang XL, Shi J, Epstein DH, Lu L (2009). Psychosocial stress after reactivation of drug-related memory impairs later recall in abstinent heroin addicts. Psychopharmacology (Berl) 203: 599-608. 